Elsevier Editorial System(tm) for Wear

Manuscript Draft

Manuscript Number: IH-3650R1

Title: 3D Characterisation of Tool Wear Whilst Diamond Turning of Silicon

Article Type: Full-Length Article

Section/Category:

Keywords: IR optics; diamond turning; diamond tool wear; tool life; silicon optics

Corresponding Author: Isidro Durazo-Cardenas,

Corresponding Author's Institution: Cranfield University

First Author: Isidro Durazo-Cardenas

Order of Authors: Isidro Durazo-Cardenas; Paul Shore; Xichun Luo; Tony Jacklin; Sue Impey; Andrew Cox

Manuscript Region of Origin:

Abstract: Nanometrically-smooth infrared silicon optics can be manufactured by the diamond turning process. Due to its relatively low density, silicon is an ideal optical material for weight sensitive infrared (IR) applications. However, rapid diamond tool edge degradation and the effect on the achieved surface have prevented significant exploitation. With the aim of developing a process model to optimise the diamond turning of silicon optics, a series of experimental trials were devised using two ultra-precision diamond turning machines. Single crystal silicon specimens $<1,1,1>$ were repeatedly machined using diamond tools of the same specification until the onset of surface brittle fracture. Two cutting fluids were tested. The cutting forces were monitored and the wear morphology of the tool edge was studied by scanning electron microscopy (SEM). 
The most significant result showed the performance of one particular tool was consistently superior when compared with other diamond tools of the same specification. This remarkable tool performance resulted in doubling the cutting distance exhibited by the other diamond tools. Another significant result was associated with coolant type. In all cases, tool life was prolonged by as much as $300 \%$ by using a specific fluid type. Further testing led to the development of a novel method for assessing the progression of diamond tool wear. In this technique, the diamond tools gradual recession profile is measured by performing a series of plunging cuts. Tool shape changes used in conjunction with flank wear SEM measurements enable the calculation of the volumetric tool wear rate. 


\title{
3D Characterisation of Tool Wear Whilst Diamond Turning Silicon
}

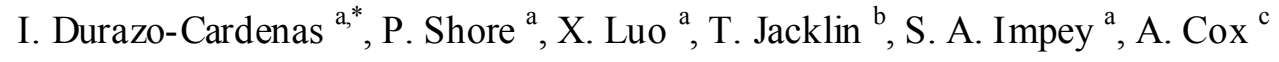 \\ ${ }^{\text {a }}$ Cranfield University, Cranfield, Bedfordshire, MK43 0AL, England \\ b Thales Optics, St Asaph, LL17 OLL, Wales \\ ${ }^{\mathrm{c}}$ Contour Fine Tooling, Wedgwood Court, Stevenage, Hertfordshire, \\ SG1 4QR, England
}

\begin{abstract}
Nanometrically-smooth infrared silicon optics can be manufactured by the diamond turning process. Due to its relatively low density, silicon is an ideal optical material for weight sensitive infrared (IR) applications. However, rapid diamond tool edge degradation and the effect on the achieved surface have prevented significant exploitation. With the aim of developing a process model to optimise the diamond turning of silicon optics, a series of experimental trials were devised using two ultraprecision diamond turning machines. Single crystal silicon specimens $<1,1,1>$ were repeatedly machined using diamond tools of the same specification until the onset of surface brittle fracture. Two cutting fluids were tested. The cutting forces were monitored and the wear morphology of the tool edge was studied by scanning electron microscopy (SEM).

The most significant result showed the performance of one particular tool was consistently superior when compared with other diamond tools of the same specification. This remarkable tool performance resulted in doubling the cutting distance exhibited by the other diamond tools. Another significant result was associated with coolant type. In all cases, tool life was prolonged by as much as $300 \%$ by using a specific fluid type.

Further testing led to the development of a novel method for assessing the progression of diamond tool wear. In this technique, the diamond tools gradual recession profile is measured by performing a series of plunging cuts. Tool shape changes used in conjunction with flank wear SEM measurements enable the calculation of the volumetric tool wear rate.
\end{abstract}

Keywords: IR optics, diamond turning, diamond tool wear, tool life, silicon optics

\footnotetext{
${ }^{*}$ Corresponding author. Tel. +(44) 1234750111 ext. 5641, Fax +(44) 1234751 172. E-mail address: i.s.durazocardenas@cranfield.ac.uk
} 


\section{Introduction}

Nanometrically-smooth infrared silicon optics can be manufactured by the diamond turning process [1] [2]. Due to its relatively low mass density, single crystal silicon is an ideal optical material for weight sensitive infrared (IR) applications. An additional benefit of silicon is its low cost when compared to other IR optic materials. Other optical applications in which diamond-turned ultra-smooth silicon surfaces exhibit great potential are X-ray optics, X-ray interferometers and MEMS components [3] [4].

During manufacture, material removal at the new surface ideally occurs in the ductile regime [5]. For the silicon substrate to be plastically deformed at the cutting plane, the use of an extremely stiff and smooth ultra-precision machine is required. This demand is needed in order to ensure the small scale of deformation required for plasticity is maintained during machining.

In practice, diamond tools degrade whilst machining silicon resulting in a rapid transition from the ductile to the brittle-fracture cutting regime. This degradation causes poor quality surfaces and often extensive subsurface damage. As a consequence, IR silicon optics technologies have not been fully exploited to date.

Despite recent contributions [6-7], understanding of the mechanisms causing tool edge degradation is still poorly understood and cannot be accurately predicted. Therefore, adequate characterisation of tool-wear behaviour, and the identification of the significant factors, is crucial to retard tool wear and consequently prolong the useful life of the tool.

Currently, diamond-tool wear is typically characterized by measuring the tool's flank wear land (VB) and/or the tool-tip profile recession using direct and indirect measuring methods. Direct methods consist of measuring the diamond-tool flank wear after cutting for predetermined lengths. This assessment is performed using microscopy techniques such as scanning electron microscopy [8] [9]. Indirect methods often consist of imprinting the tool 
profile onto a 'softer' more malleable material by a plunge cut or an indentation. Subsequently these are measured using microscopy techniques or profilometry [10] [11]. A more robust and practical characterisation method would be an advantage to aid tool wear progression understanding.

This paper presents the results of a series of meticulously designed and performed diamond turning experiments. The influence of the type of cutting fluid and the tools top rake angle on tool life has been investigated. This work has also developed a new technique to characterise diamond tool wear whilst single point diamond turning.

\section{Experimental}

\subsection{Experimental procedures}

Two experiments were devised with the aim of developing a process model to optimise the diamond turning of silicon optics.

Experiment 1 was designed to investigate the effect of coolant type on the diamond tool life. The application of coolant has been shown to have a significant effect on the life of diamond tools compared with dry cutting, yielding longer cutting distances [6]. Two different coolants were tested, fluid 'A' and fluid 'B'. Fluid 'A' is a water-based machining coolant, whereas fluid 'B' is an oil-based coolant commonly used in diamond turning. Some important physical properties of fluids A and B are shown in Table 1. Both coolants were applied using an evaporative spray mist system. The test specimens were single crystal silicon with a crystal orientation $<1 \quad 1 \quad 1>$, a diameter of $50 \mathrm{~mm}$ and a thickness of $5 \mathrm{~mm}$. Four Contour Fine Tooling diamond tools of identical specification, $0.5 \mathrm{~mm}$ tool nose radius, $-25^{\circ}$ top rake angle and $10^{\circ}$ clearance were used for all the machining trials in Experiment 1. 
The machining parameters employed are shown in Table 2. These parameters were established in previous experimentation [12], and ensure adequate conditions for the machining of optical-quality silicon surfaces.

The cutting operations in Experiment 1 consisted of performing repetitive $10 \mu \mathrm{m}$ deep facing cuts using one of the two coolant types until brittle fracture was observed on the surface of the specimen. A duplicate specimen was machined to establish the experiment's repeatability. The diamond tool-coolant type arrangement used in Experiment 1 is shown in table 3.

The experimental response was measured in terms of cutting distance $(\mathrm{km})$ before the onset of brittle fracture. Cutting forces were monitored for each of the cutting iterations. SEM was used to study the morphology of tool edge wear at the end of each test. Prior to machining, a $1 \mathrm{~mm}$ diameter recess was removed from the centre of all specimens to avoid machining where the cutting speed approached zero. With the conditions described in Table 2, the cutting distance reached at the end of each cut was approximately $1.81 \mathrm{~km}$.

Experiment 2 was designed to study progressive tool wear, as well as investigating the effect of the tool top rake angle on the life of the diamond tool. The specimens were single crystal silicon specimens with crystal orientation $<111>$ of $100 \mathrm{~mm}$ diameter and $5 \mathrm{~mm}$ thickness. Three Contour Fine Tooling diamond tools having top rake angles of $-15,-25$ and $-45^{\circ}$ with a $0.5 \mathrm{~mm}$ tool nose radius and $10^{\circ}$ clearance were used. The results observed in Experiment 1 were incorporated in to Experiment 2 by using the coolant type that yielded the longer cutting distance.

In Experiment 2, the cutting operations consisted of performing a series of plunge and facing cuts, until the onset of brittle fracture. Tool plunges were carefully performed to a depth of 
$20 \mu \mathrm{m}$ at a $0.2 \mu \mathrm{m} / \mathrm{rev}$ in-feed rate, in a central 'reserved' area of the specimens. An initial plunge produced an imprint of the 'fresh' diamond-tool edge prior to cutting. Subsequent tool plunges were performed after each facing operation. Facing operations were performed using the cutting parameters described in Table 2. After the in itial facing operation, the traverse distance was reduced by $1 \mathrm{~mm}$, proportionally reducing the cutting distance. This series of tool plunges and facing cuts resulted in a concentric tool imprint pattern, as well as a 'stepped' profile from the facing operations, see Figure 1. The sequence of plunge-traverse cutting continued until the brittle fracture was visually observed on the face machined surface of the specimen.

The experimental response was measured in terms of cutting distance $(\mathrm{km})$. Cutting forces were also monitored. Surface finish assessment was performed on the cut surface using a Wyko-Topo 3D phase shift interferometer.

Tool wear was examined directly on the diamond tools using a FEI XL30 environmental scanning electron microscope (ESEM) by measuring the tool flank wear land (VB) after each

plunge cut. In addition, the recession of the diamond tool cutting edge was examined by measuring the plunge 'imprint' profiles via a Talysurf surface profilometer. Optical micrographs complemented the cutting edge assessments.

All specimens were chamfered and etched on both sides prior to testing in order to remove possible entrapment of contaminants and to produce stress free surface conditions.

\subsection{Equipment}

Initial single point diamond turning tests were carried out on a high performance diamond turning machine, the NION Nanocentre. The machine rigid structure, highly accurate temperature and motion control of the NION Nanocentre [13] ensured repeatability across the numerous tests, whilst a precise optical tool-set station enabled the diamond tools to be 
accurately repositioned. Subsequent confirmation tests were carried out on a Moore UPL350. The Moore UPL 350 is a commercially available ultra-precision lathe also capable of machining ultra-smooth IR optics. The most significant difference between the two machines resides in the type of work-head spindle. The NION Nanocentre uses an oil hydrostatic bearing spindle, whereas the Moore UPL350 uses an aerostatic bearing spindle.

A 3-component force dynamometer unit (Kistler 9257-BA) was installed in both machines to monitor cutting forces.

\section{Results and discussion}

\subsection{Effect of coolant on tool life (Experiment 1)}

Figure 2 illustrates the cutting distance achieved by the different diamond tools using fluids A and B. As can be seen in Figure 2, the cutting distance was favoured by the adoption of cutting fluid 'A'. In all cases where cutting fluid 'A' was used, the diamond tool life was prolonged; in extreme cases by as much as 300\%. Although not well understood yet, coolant type affinity to diamond turning of single crystal silicon has been reported previously [6]. The heat removal capacity of coolants is widely acknowledged as a determinant which can influence cutting distance and even the coolant's molecular characteristics have been suggested as a factor for improved cutting [14]. In this sense, fluid 'A' has a higher specific heat than fluid ' $\mathrm{B}$ ' and this might have accounted for the improved performance.

On closer inspection of Figure 2 it is also evident that the cutting distance achieved by tool \#3 distinctly exceeded that achieved by tools \# 1,2 and 4. As the specification of the diamond tools was the same and the cutting conditions kept constant throughout the experiment, these results were not expected.

Because of the extended cutting distance shown by tool \#3, a confirmation trial (trial 2) was consequently run. In this new trial, the sequence of diamond tool with coolant type was inter- 
changed in order to examine the possible effects of the individual tool performance. In preparation for trial 2, the diamond tools were re-lapped to an 'as new' condition. The same ultra-precision machine and cutting conditions were used. As seen in Figure 2, the observed results from trial 2 correlated well with the results from the previous trial. Again, the diamond tools where fluid ' $\mathrm{A}$ ' was u sed yielded longer cutting distances. More importantly, it was also noticed that tool \# 3, despite the less favourable fluid ' $\mathrm{B}$ ' coolant exhibited a cutting distance that was comparable to diamond tools \# 1,2 and 4 when fluid 'A' was used. A third trial was conducted on the Moore UPL 350 machine with the purpose of confirming these results. Once again, similar results were observed, suggesting that to a certain extent, the results observed are independent of machine-tool performance for machines of this quality. From these results it was observed that diamond tool \#3 consisten tly achieved superior cutting distances, at least twice the cutting distance achieved by diamond tools \# 1, 2 and 4.

The results from these trials show that re-lapping the diamonds tools between trials does not generate any significant effects. It should also be noted, that in the present study thermal effects arising from the use of any of the coolants have not been quantified.

The measured cutting forces showed that for the present conditions, only the magnitude of the normal force component was significant, and that this generally increased with the cutting distance. Conversely, the change of magnitude of cutting and feed forces was found to be marginal throughout the trials. Figure 3 illustrates the normal cutting force against cutting distance achieved before the onset of brittle fracture. On inspection of these results, it was found that the normal cutting force resulting from each diamond tool varied when the different coolant types were used. A significant influence of the coolant type on the observed normal cutting force level is quite evident. 
For analysis purposes, Figure 3 has been divided in three zones:

- Zone I accommodates the normal force traces of tool \#3 when using fluid 'A'. It can be seen that the normal force gradient is lower than the rest. Thus monitoring of the normal cutting force also indicates the superior performance of tool \#3.

- Zone II accommodates the normal force for diamond tools 1, 2 and 4 when fluid ' $A$ ' was used. It also accommodates the normal force trace for diamond tool \#3 when fluid 'B' was used.

- Zone III accommodates the normal force traces for diamond tools 1 and 2 when fluid 'B' was used. As can be seen, the cutting force traces in Zone III exhibit the highest force gradients, and hence the shortest tool life.

These results suggest that as the diamond tool wears the contact area between the diamond tool edge and the work-piece gradually increases resulting in an increased normal cutting

force. A similar mechanism has been also described by other authors [6]. From the observed results for diamond tool \#3, it is also suggested that the attributes of individual diamond gems play a very significant role. Meticulous re-examination of similar published analyses revealed some instances of 'superior' tools with improved wear characteristics [7] [15] [16]. At present, however, it is not clear what are the attributes of superior single crystal diamond tools.

\subsection{Effect of top rake angle (Experiment 2)}

The results from experiment 2 showed that the diamond tool with the $-25^{\circ}$ top rake angle exhibited the best performance, providing a useable cutting distance of $35 \mathrm{~km}$ before the onset of brittle fracture. A comparative performance was exhibited by the diamond tool with $a-15^{\circ}$ top rake angle reaching $24 \mathrm{~km}$ before brittle fracture occurred. Finally, the weakest 
performance was obtained with the $-45^{\circ}$ tool achieving approximately $20 \mathrm{~km}$ before the onset of brittle fracture. Single point diamond turning of brittle materials in the ductile mode has been reported to be more conducive when negative top rake angles are used [17] [18]. The favourable effect of the negative rake an gle is attributed to the increased compressive stresses generated at the cutting plane, facilitating plastic removal. However as observed in experiment 2 , this was not the case for the $-45^{\circ}$ tool. This result contradicts the results from a previous study [7] where larger negative angles resulted in reduced tool wear. No obvious reason was observed for this behaviour, although variability of diamond gem performance is suspected.

In all cases, visually observed brittle fracture was confirmed by examining roughness $\left(R_{a}\right)$ at the specimens' cut surface using the Wyko-Topo interferometer and a Nomarski optical microscope. The values measured along the most severely damaged fracture arms clearly exceeded $10 \mathrm{~nm} \mathrm{R}_{\mathrm{a}}$, signalling the ductile to brittle cutting mode transition.

\subsection{SEM tool wear observations}

The mechanism of the gradual diamond-tool wear was observed using SEM. It can be described as initial attritious wear that subsequently leads to micro-cracking and then chipping. Soon after the start of the cut, the sharp cutting edge recedes and flank wear becomes predominant on the approaching edge [6]. As wear progresses, at about $5 \mathrm{~km}$ cutting distance, the bulk of the flank wear transfers to the central part of the tool's nose and then subsequently to the trailing edge. Further cutting leads to the gradual increase of the flank wear land (VB). This results in a loss of clearance angle, which increases the tool to work-

piece contact area. As the flank wear land continues to grow, brittle fracture cutting occurs. Some edge micro-chipping is observed but this appears not to be the prerequisite for a brittle fracture cutting mode. At this point, it is possible that rapid degradation of the diamond tool edge modifies the tool's geometry sufficiently to cause the material removal mode to transfer 
from plastic to fracture based removal. Figure 4 illustrates a typical worn cutting edge after reaching brittle fracture cutting mode.

Figure 5 illustrates the results of the measured maximum flank wear land (VB max) using SEM for a $-25^{\circ}$ top rake angle diamond tool when using fluid ' $\mathrm{A}$ '. The wear on the flank land increases with the cutting distance. The trend may be split into three regions. In the first region, from the start of the cut until the cutting distance approaches $18 \mathrm{~km}$, the tools sharp edge wears displaying an almost linear growth trend. It then reaches a steady-state phase that lasts for approximately $10 \mathrm{~km}$. Finally, in the third region, an accelerated wear phase develops that subsequently leads to brittle fracture. Although different in nature, similar trends have been presented by other authors [19] [20].

Figure 6 illustrates the normal force results for the plunge cuts. The magnitude of the normal force gradually increases with the cutting distance. As seen in Figure 5 wear of the flank land increases with the cutting distance, thus the contact area between the tool and the work-piece increases. This results in an increase in friction as well as the magnitude of the normal cutting force, as observed in Figure 6.

\section{Tool wear characterisation}

In the present study, tool wear characterisation is based on the assessment of the material loss that typically occurs on the tools rake and the clearance face, as illustrated in Figure 7 (a). For analysis purposes, the wear region can be divided into a series of wear sections along the cutting edge. Figure 7(b) illustrates a section of a typical worn tool. Wear is present in both the rake face and the clearance face. The average length of the line AC is defined as flank wear land (commonly denoted as VB). The absolute value of rake angle and clearance angle are represented by $\alpha$ and $\beta$, respectively. 


\subsection{Assessment of tool wear area}

Assessment of the tool wear area was carried out by measuring the profile of the plunge cuts using a Form Talysurf surface profilometer. Figure 8 shows a top view of a worn diamond tool showing schematically the principle of the calculation of the wear area $\left(W_{a}\right)$. For clarity, the true scale of $W_{a}$ in Figure 8 has been exaggerated. From Figure 8 the wear area $\left(W_{a}\right)$ can be expressed as:

$$
W_{a}=\overline{d R} \cdot W_{L}
$$

Where $d R$ represents the av erage wear value and $W_{L}$ is the wear length.

Figure 9 shows a typical measured tool-tip profile. As illustrated in Figure 9, wear mainly occurs somewhere in the region between the line $L$ and the line $R$. In order to assess tool tip recession more accurately, least square arc analysis was performed on the acquired profiles, excluding the data from the L-R region from the analysis. By modifying the analysis in this manner, a clearer picture of the worn area is observed. The L-R region was defined by positioning the line $L 10 \mu \mathrm{m}$ away from the left edge of profile and the line $R 40 \mu \mathrm{m}$ away from the centre of the tool tip. This definition was a conservative estimate of the cutting edge wear region and selected to reduce the impact of variations in the profile due to experimental error. Optical micrographs were used to corroborate these assumptions.

Figure 10 illustrates the modified analysis for the tool tip profile shown previously in Figure 9. As observed in Figure 10, the wear profile is more clearly defined, whereas the unworn region profile, defined outside the $L-R$ region, virtually superimposed on the x-axis, reflecting the suitability of the curve fitting. From this modified profile the average profile height $P_{a}$, 
which represents the average reduction of tool radius due to wear, and the profile length $P_{L o}$ are estimated. The wear area, $W_{a}$, can then be estimated as:

$$
W_{a}=P_{a} \cdot P_{L o}-P_{\text {anew }} \cdot P_{\text {lonew }}
$$

Where $P_{\text {anew }}$ is the wear region average height and $P_{\text {lonew }}$ is the length of the original 'unused' tool-tip profile. From these data $\left(W_{a}\right)$ and figure $7(\mathrm{~b})$, the wear area on the rake face $\left(W_{a r}\right)$ can be estimated as:

$$
W_{a r}=\frac{W_{a}}{\cos \alpha}
$$

Figure 11 shows the variation of the calculated wear area with the cutting distance when diamond tools with $-15,-25$ and $-45^{\circ}$ top rake angle were used. Figure 11 illustrates that when diamond tools have rake angles of -25 and $-15^{\circ}$ significantly less wear occurred than compared with a $-45^{\circ}$ tool. These results are consistent with the initial tool top rake angle versus cutting distance findings. They also support the observed escalating trend of the normal cutting force with cutting distance shown in Figures 3 and 6.

\subsection{Three dimensional characterization of tool wear}

Based on the measurements of tool wear area and flank wear land, the wear volume of the diamond tool can be estimated by integrating the receding wear area sections along the tool profile, as illustrated schematically in Figure 12. Therefore, wear volume $\left(W_{v}\right)$ can be expressed as: 


$$
W_{v}=\int_{0}^{W_{L}} \frac{1}{2} \overline{B C} \cdot \overline{A B} \cdot \sin (\angle A B C) d W_{L}
$$

Where $\overline{B C}$ and $\overline{A B}$ are the wear length on the rake face and the clearance face respectively. $\angle A B C$ is the angle between them. $\overline{A B}$ can be also expressed as:

$$
\overline{A B}=\frac{\operatorname{aver}(\overline{d R})}{\cos \alpha}
$$

By substituting (5) into Equation $4, W_{v}$ can be approximated as:

$$
W_{v} \approx \frac{1}{2} \overline{B C} \cdot \frac{\operatorname{aver}(\overline{d R})}{\cos \alpha} \cdot W_{L} \cdot \sin (\angle A B C) \approx \frac{1}{2} \overline{B C} \cdot \frac{W_{a}}{\cos \alpha} \cdot \sin (\angle A B C)
$$

Using the law of sines, $\overline{B C}$ can be expressed as:

$$
\overline{B C}=\frac{\overline{A C} \cdot \sin \angle B A C}{\sin \angle A B C}
$$

Where the length of $\overline{A C}$ equals the length of the flank wear (VB). The angle $\mathrm{ABC}$ can be then expressed as:

$$
\angle A B C=\frac{\pi}{2}-\alpha-\beta
$$

The angle BCA can be also estimated by using the law of sines: 


$$
\angle B C A=\arcsin \left(\frac{\overline{A B} \cdot \sin (\angle A B C)}{\overline{A C}}\right)
$$

Finally, the following relationship is obtained:

$$
\angle B A C=\pi-\angle A B C-\angle B C A=\frac{\pi}{2}+\beta-\alpha-\arcsin \left(\frac{\overline{A B} \cdot \sin \angle A B C}{\overline{A C}}\right)
$$

Thus, the wear volume $W_{v}$ can be estimated by using equations (6) to (10).

Figure 13 shows the estimates of the wear length on the rake face $(\overline{A B})$, the clearance face $(\overline{B C})$ and the flank wear (VB) based on the above equations. The resulting wear length on the clearance face as well as the flank wear land is much larger than that on the rake face. Wear on the rake face $(\overline{A B})$ develops steadily as the diamond tool quickly loses its sharp cutting edge at the beginning of cut. However, after the cutting distance has reached $20.97 \mathrm{~km}$, the wear length on the top rake face decelerates.

On the other hand, the wear length on the clearance face $(\overline{B C})$ follows that of the flank wear (VB) very closely, also developing steadily. Both reach a steadier phase after a cutting distance of approximately $21 \mathrm{~km}$, before the wear length begins developing at a higher rate. Finally, after reaching a cutting distance of $30.2 \mathrm{~km}$, the trends separate and the length of the flank wear surpasses that of the clearance face. From this behaviour, a layer by layer wearremoval mechanism of the diamond gem on the clearance face is suggested during this phase. 
The calculated increase in wear volume as a function of the cutting distance is illustrated in Figure 14. As observed in Figure 14, soon after the sharp cutting edge recedes, an accelerated volumetric tool wear rate phase follows. This phase continues until the cutting distance reaches approximately $21 \mathrm{~km}$. After this, the volumetric tool wear rate decreases slightly for an approximate cutting distance of $10 \mathrm{~km}$, prior to the volumetric wear rate reverting to a similar rate observed in the initial phase. During the final phase the ons et of brittle fracture is experienced.

To the authors' knowledge, estimating the wear area and volumetric wear of diamond tools progressively is novel in diamond turning silicon. This information provides new insight in to the development of diamond turning silicon. The technique is believed to be valuable to gain an understanding of individual diamond gem quality.

\section{Conclusions}

1. The influence of the diamond gem on tool life of single point diamond tools appears to be very significant. Amongst diamond tools of the same specification, made by the same manufacturer, particular 'superior' gems exhibited lower force gradients, and consistently achieved at least twice the cutting distance observed by 'average' diamond gems under the same cutting conditions. Further work needs to be carried out in this area in order to establish the attributes of a 'superior' gem.

2. Coolants significantly influence the diamond tool wear rate and the normal cutting force. It was found that the useful life of diamond tools can be prolonged up to $300 \%$ by the use of a specific coolant.

3. The observed wear mechan ism of diamond tool edge can be described as one based on; initial attritious wear that subsequently leads to micro-cracking and then chipping. The recorded flank wear land (VB max) initially exhibits an approximate linear trend. 
A steady phase is then reached followed by a stage of accelerated growth which finally leads to brittle fracture.

4. Diamond tools with a top rake angle of $-25^{\circ}$ proved to be more conducive to diamond turning silicon with the present conditions, yielding longer cutting distances than - 15 and -45 degree diamond tools. This finding is clearly subject to the influence of conclusion 1.

5. A new technique for the evaluation of gradual tool wear has been developed. This new technique provides a novel insight into the evolution of the gradual diamond tool wear mechanism. Based on the tools gradual recession profile in conjunction with the measurement of progressive flank wear land, an estimate of the volumetric wear rate can be calculated. 


\section{References:}

1. P. Parr-Burman, P. Shore, Diamond turning of silicon optics, Proceedings of SPIE, Vol. 2775 (1996) 575-584.

2. N. Asida, B. Ben-Menachem, Latest advances in the design and manufacture of large diameter diffractive \& aspheric silicon elements for IR lens assemblies, Proceedings of SPIE Vol. 4820 (2003) 780- 789.

3. M. Weck, Fischer S, Manufacturing of Microstructured Surfaces using Ultra-precision turning, milling and shaping, Proceedings of EUSPEN Vol. 1, Bremen, Germany, May $31^{\text {st }}-$ June $4^{\text {th }},(1999) 420-423$.

4. L. De Chiffre, H. Kunzmann, G. N. Peggs, D. A. Lucca, Surfaces in precision engineering, micro engineering and nanotechnology, Annals of the CIRP Vol. 52/2 (2003) 561-577.

5. W. S. Blackley, R. O. Scattergood, Ductile-regime machining model for diamond turning of brittle materials, Precision Engineering 13/2 (1991) 95-103.

6. J. Yan, K. Syogi, J. Tamaki, Some observations on the wear of diamond tools in ultraprecision cutting of single-crystal silicon, Wear Vol. 255 (2003) 1380-1387.

7. D. K. Born, W. A. Goodman. An empirical survey on the influence of machining parameters on tool wear in diamond turning of large single-crystal silicon optics. Precision Engineering 25/4 (2001) 247-257.

8. S. Asai, Y. Taguchi, K Horio, T. Kasai, A. Kobayashi. Measuring the very small cutting edge for a diamond tool using a new kind of SEM having two detectors. Annals of the CIRP 39/1 (1990) 85-88. 
9. M. Sharif Uddin, K. H. W. Seah, X. P. Li, M. Rahman, K. Liu, Effect of crystallographic orientation on wear of diamond tools for nano-scale ductile cutting of silicon, WEAR 257 (2004) 751-759.

10. X. P. Li, M. Ramahan, K. Liu, K.S Neo, C. C. Chan. Nano-precision measurement of diamond tool edge radius for wafer fabrication, Journal of Materials Processing Technology 140 (2003) 358-362.

11. C. K Syn, J. S. Taylor, R. R. Donaldson, Diamond tool wear vs. cutting distance on electroless nickel mirrors, Proceedings of SPIE Vol. 676 (1986) 128-140.

12. P. Shore, Assessment of the precision and cost effectiveness of direct machining hybrid type optical surfaces for IR applications, Proceedings of SPIE Vol. 2576 (1995) 426-431.

13. K. Carlisle, J. Fitzpatrick, P. Mckeown, P. Shore, Review of the Ultra Precision Machininig Research Facility- the 'NION' machine, Proceedings of the 3rd International Conference on Ultra Precision in Manufacturing Engineering UME3, (1994) 89-93.

14. D. Chargin, Cutting fluid study for single crystal silicon, Proceedings of ASPE spring topical meeting Vol. 17 (1998) 59-62.

15. X. P. Li, T. He, M. Rahman, Tool wear characteristics and their effects on nanoscale ductile mode cutting of silicon wafer, Wear 259 (2005) 1207-1214.

16. J. Wilks, Performance of diamond as cutting tools for precision machining, Precision Engineering Vol. 2/2 (1980) 58-71.

17. R. O. Scattergood, N Blake, Ductile-regime machining of germanium and silicon, Journal of the American ceramic society 73/4 (1990) 949-957.

18. T. P. Leung, W. B. Lee, X. M. Lu, Diamond turning of silicon substrates in the ductile-regime, Journal of Materials Processing Technology 73 (1998) 42-48. 
19. Y. Altintas, Manufacturing Automation, Cambridge University Press, UK, 2000, $57-$ 59.

20. M. Stanford, P. M. Lister, Investigation into the relationship between tool wear and cutting environments when turning EN32 steel, Industrial Lubrication and Technology $56 / 2(2004) 114-121$. 
Figure 1. Machining operations performed in experiment 2.

Figure 2. Cutting distance achieved by tool number and coolant type.

Figure 3. Normal cutting force results for all trials, experiment one.

Figure 4. SEM micrograph of a diamond tool cutting edge after a cutting dis tance of $22 \mathrm{~km}$ (expe riment 1 , tool \#1, 2nd trial).

Figure 5. SEM measured flank wear.

Figure 6. Tool plunges - normal cutting force monitoring res ults.

Figure 7. (a) Definition of VB. (b) Diamond-tool wo rn tool section.

Figure 8. Tool-wear a rea assessment sketch, showing the definition of $\mathrm{dR}$ and WL.

Figure 9. Typical Talys urf profile of a worn diamond tool-tip.

Figure 10. Modified LS a rc a nalys is of a worn diamond tool tip Talysurf profile.

Figure 11. Variation of the wear area with the cutting dis ta nce by tool top rake angle.

Figure 12. Typical diamond tool tip recession due to wear.

Figure 13. Calculated progressive diamond tool wear length.

Figure 14. Wear volume vers us cutting dis ta nce. 


\section{Physical p roperty}

Specific Heat@20C

(KJ/Kg K)

Density@20ㄷ $\left(\mathrm{g} / \mathrm{cm}^{3}\right)$
Fluid Type A

4.18

0.998

0.658
Fluid Type B

1.86

0.803

1.49

$\left(\mathrm{mm}^{2} / \mathrm{s}\right)$

Table 1. Typical physical properties of fluids ' $A$ ' and ' $B$ ' 
Machining Pa rameter

\begin{tabular}{cc}
\hline Cutting speed & $600 \mathrm{rpm}$ \\
Depth of cut & $10 \mu \mathrm{m}$ \\
Feed rate & $1 \mu \mathrm{m} / \mathrm{rev}$ \\
\hline
\end{tabular}

Table 2. Machining parameters used 


\begin{tabular}{ll}
\hline Tool \# & Coolant Type \\
1 & B \\
2 & B \\
3 & A \\
4 & A \\
\hline Table 3. Dia mond tool-coolant type arrangement for Experiment 1 &
\end{tabular}

Table 3. Dia mond tool-coolant type arrangement for Experiment 1 
flick here to download high resolution image

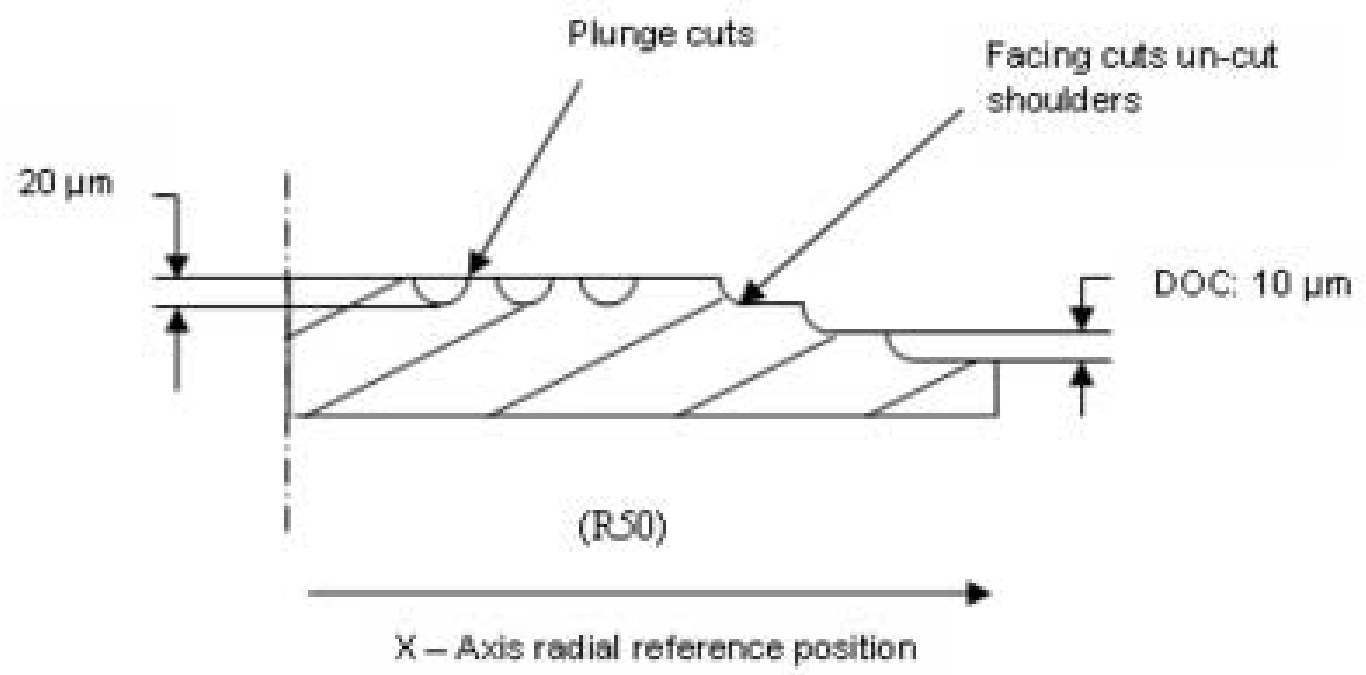




\section{figure 2}

Click here to download high resolution image

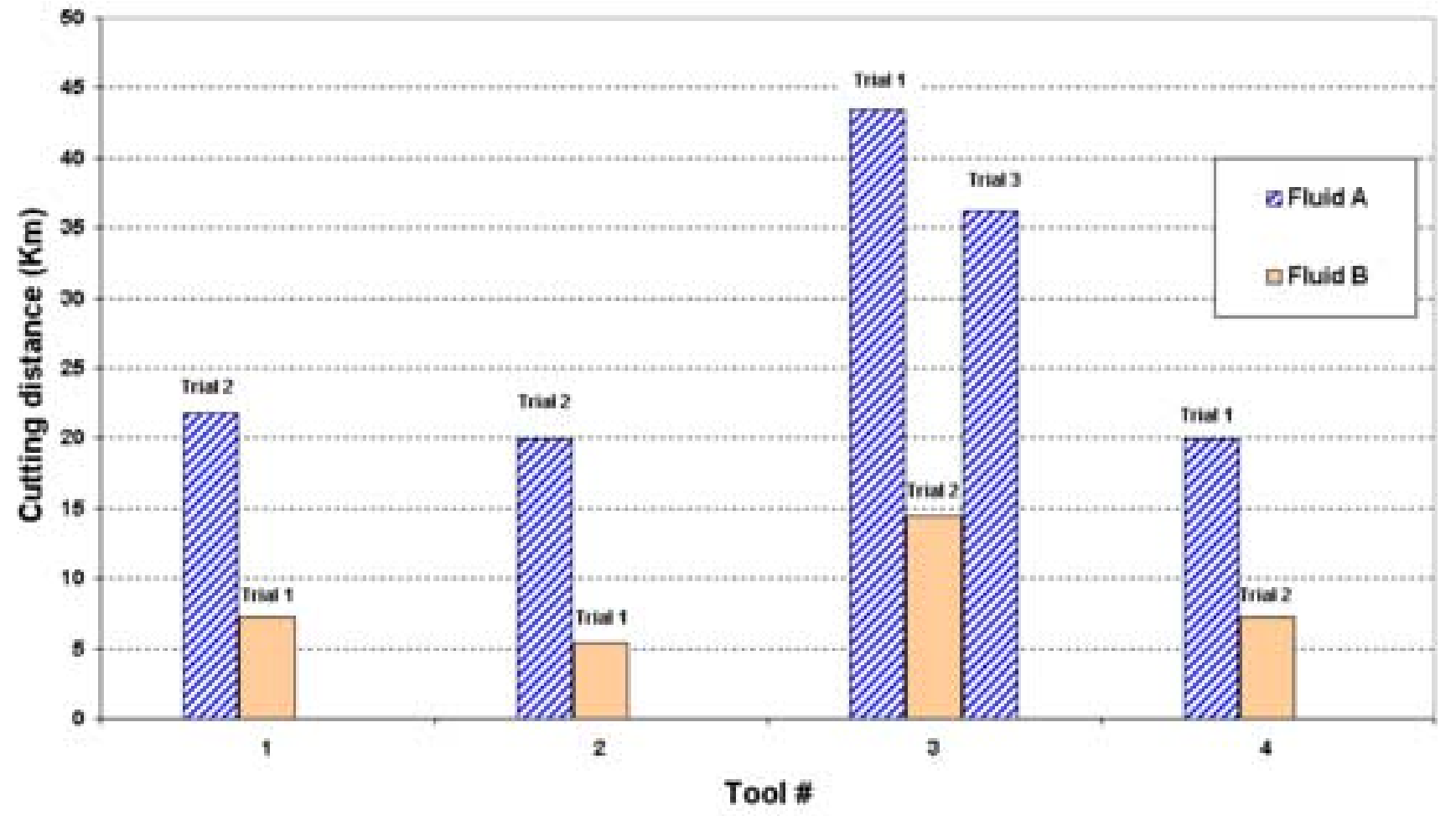




\section{figure 3}

Click here to download high resolution image

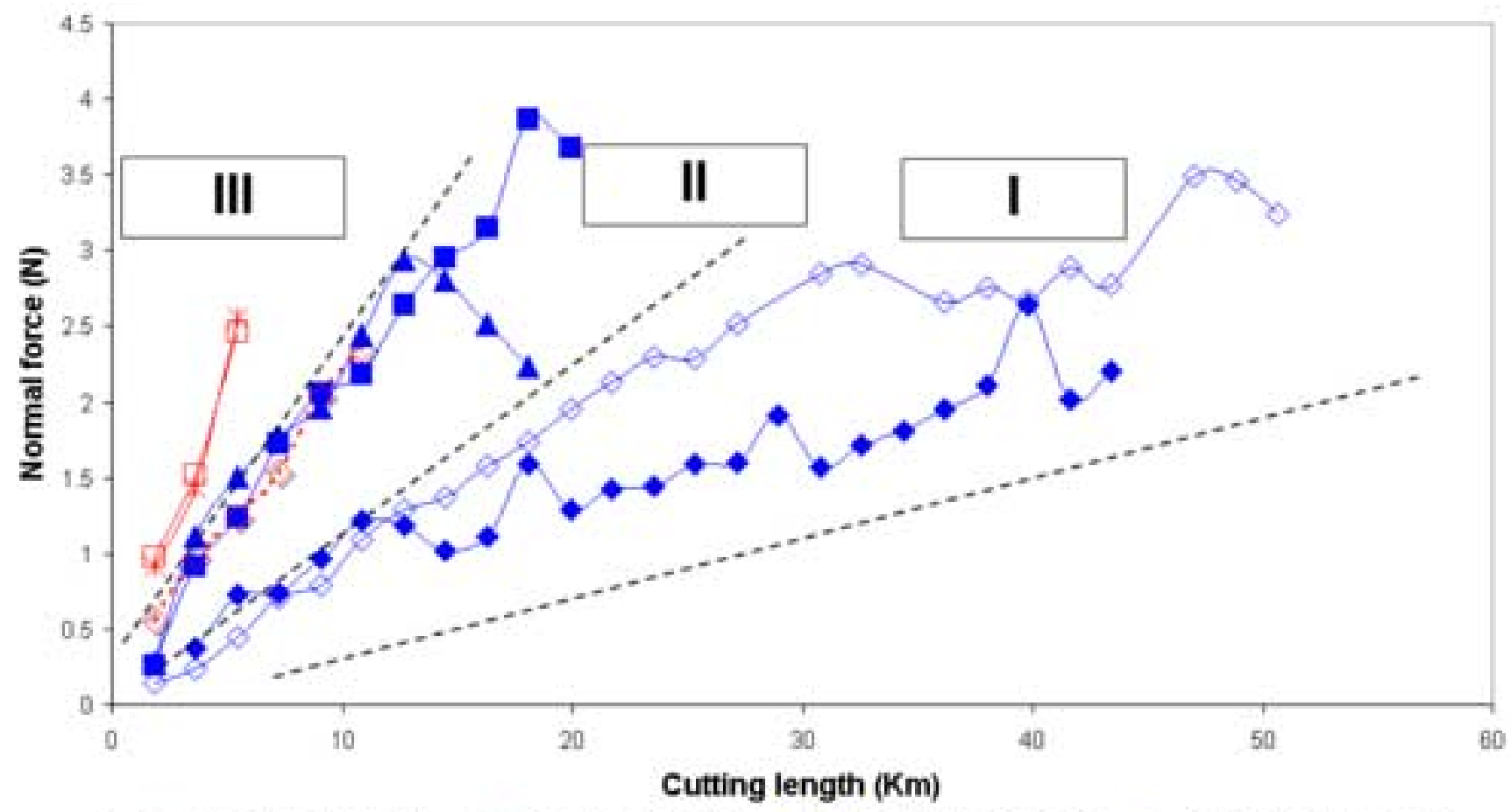

-F Flad B-Tool 1-tria 1 - E-Fud B-Tool 2-trial 1

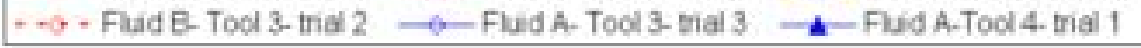


figure 4
Click here to download high resolution image

\section{Top rake face}

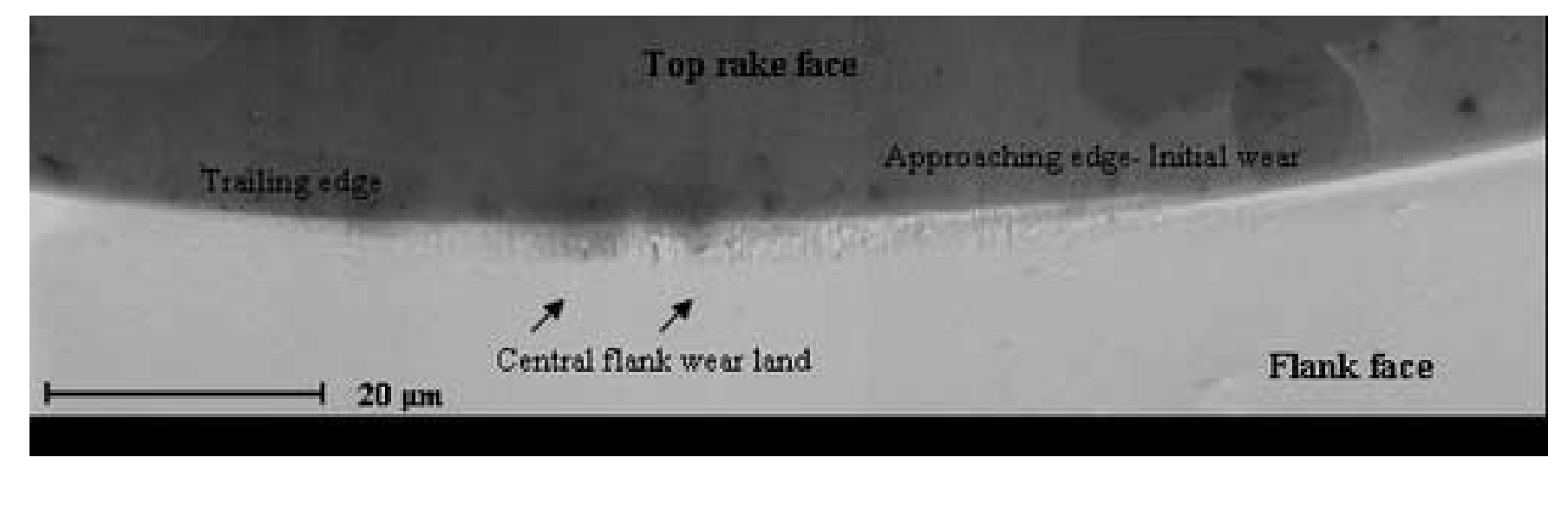

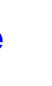

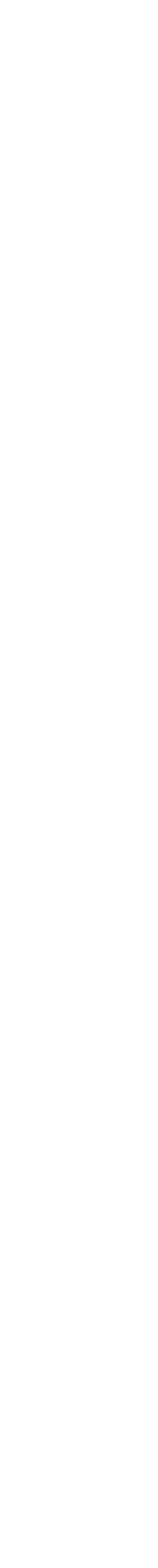


Click here to download high resolution image

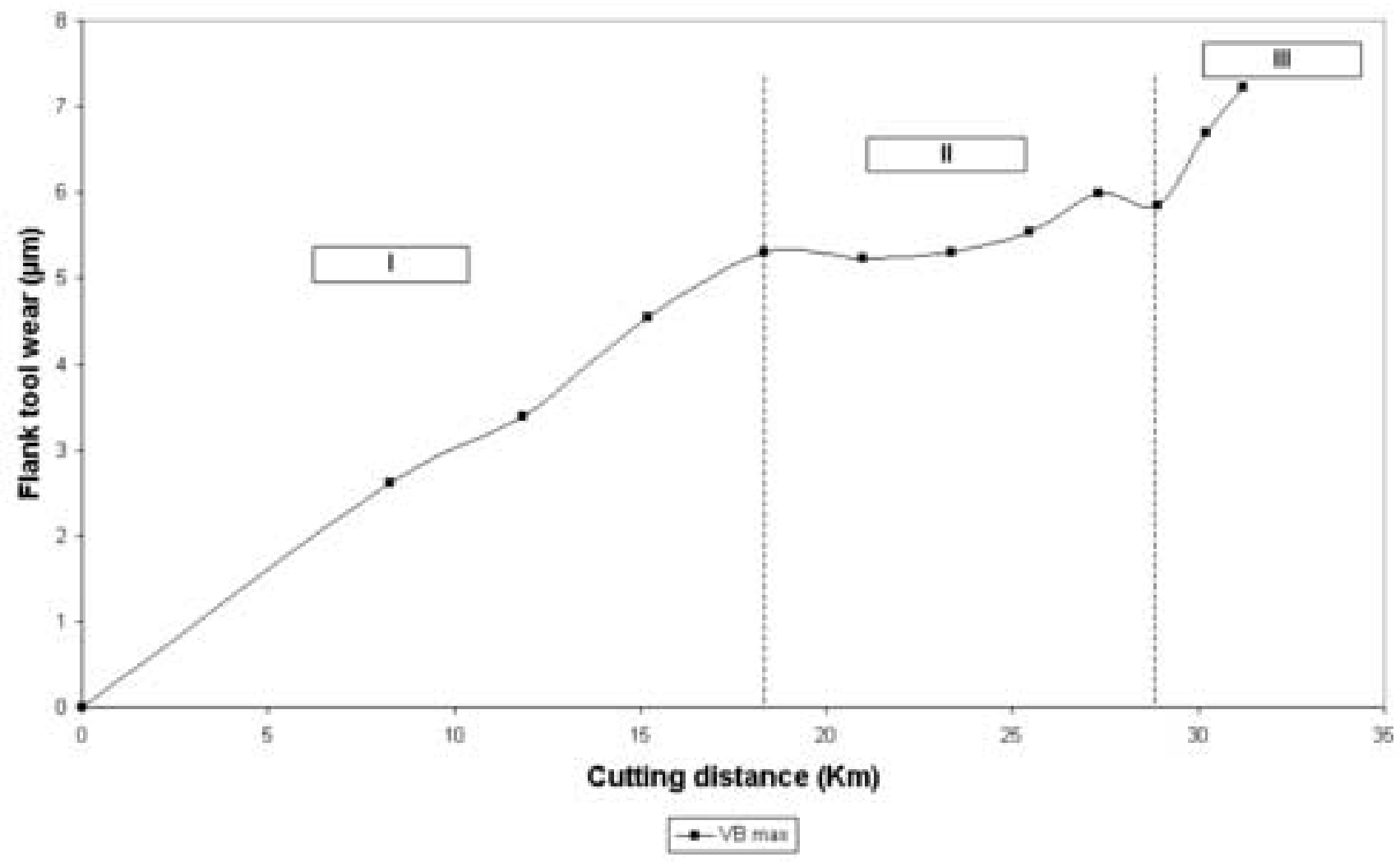




$$
=0
$$




\section{figure 7}

Click here to download high resolution image
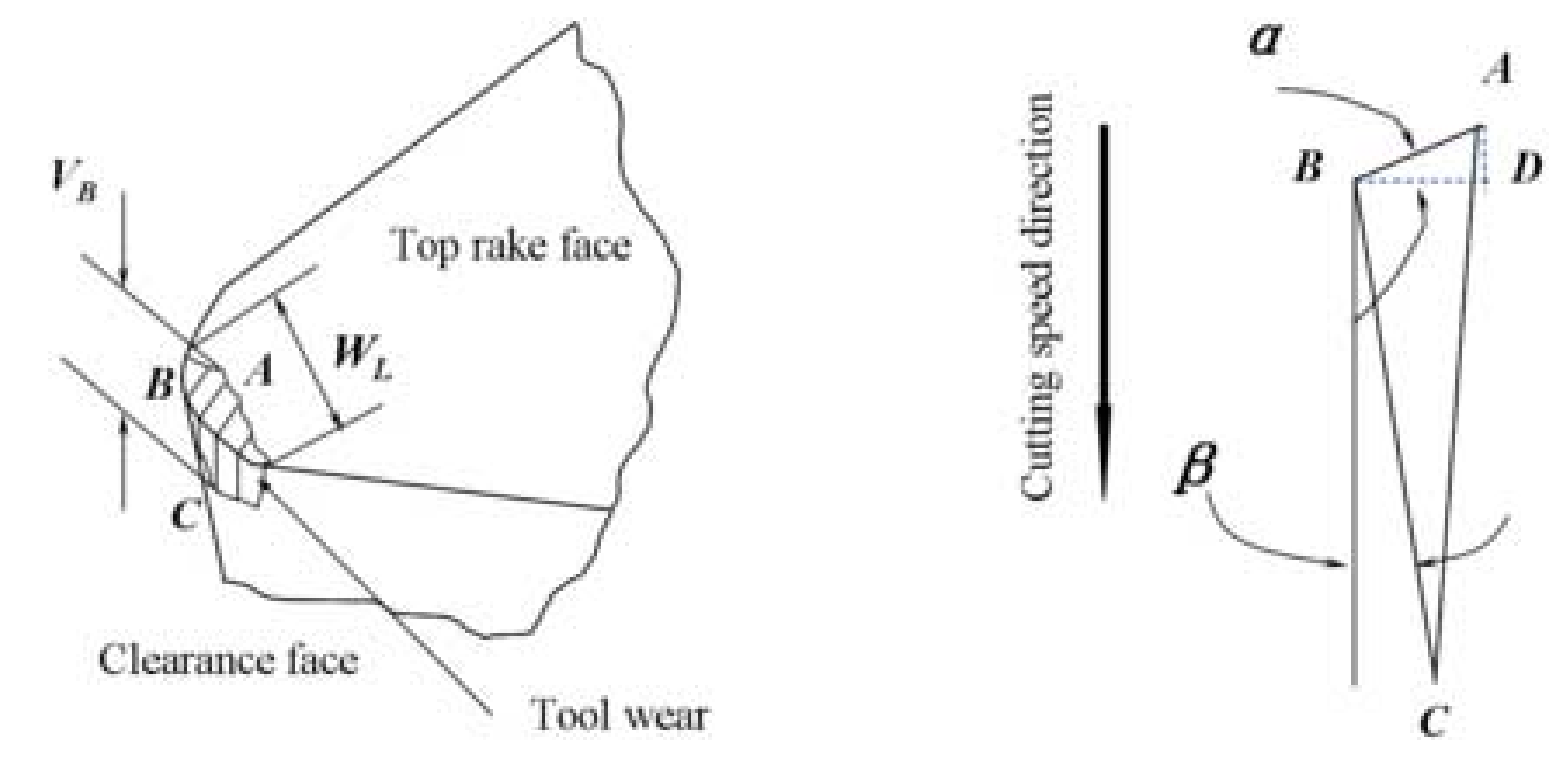
Click here to download high resolution image

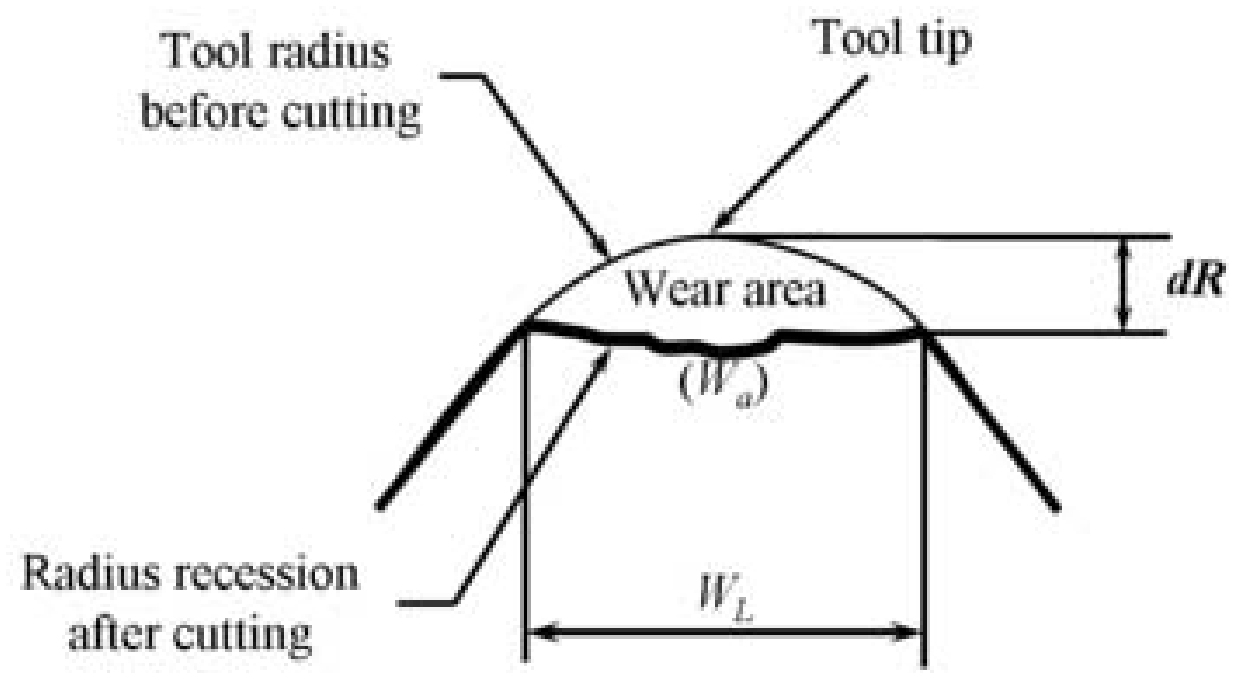


Click here to download high resolution image

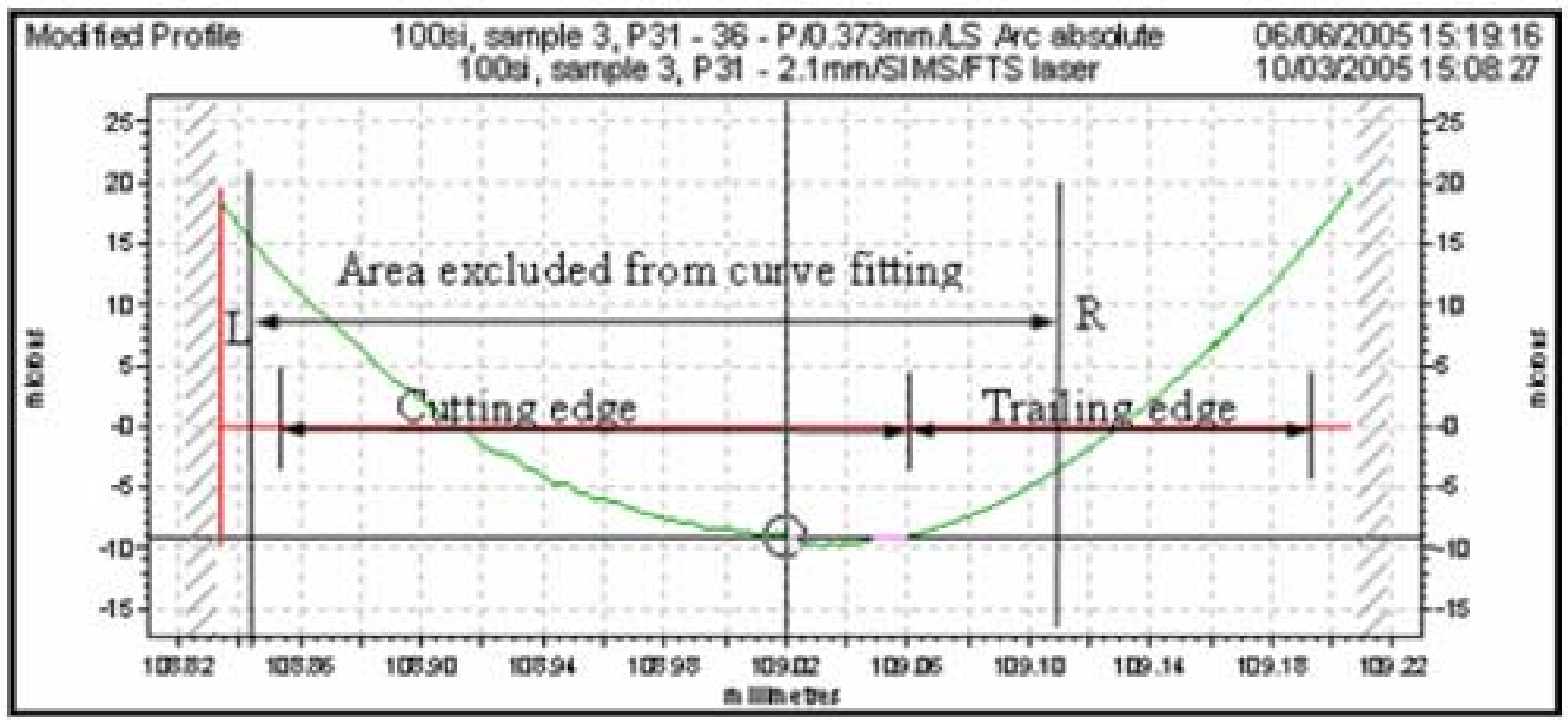


Click here to download high resolution image

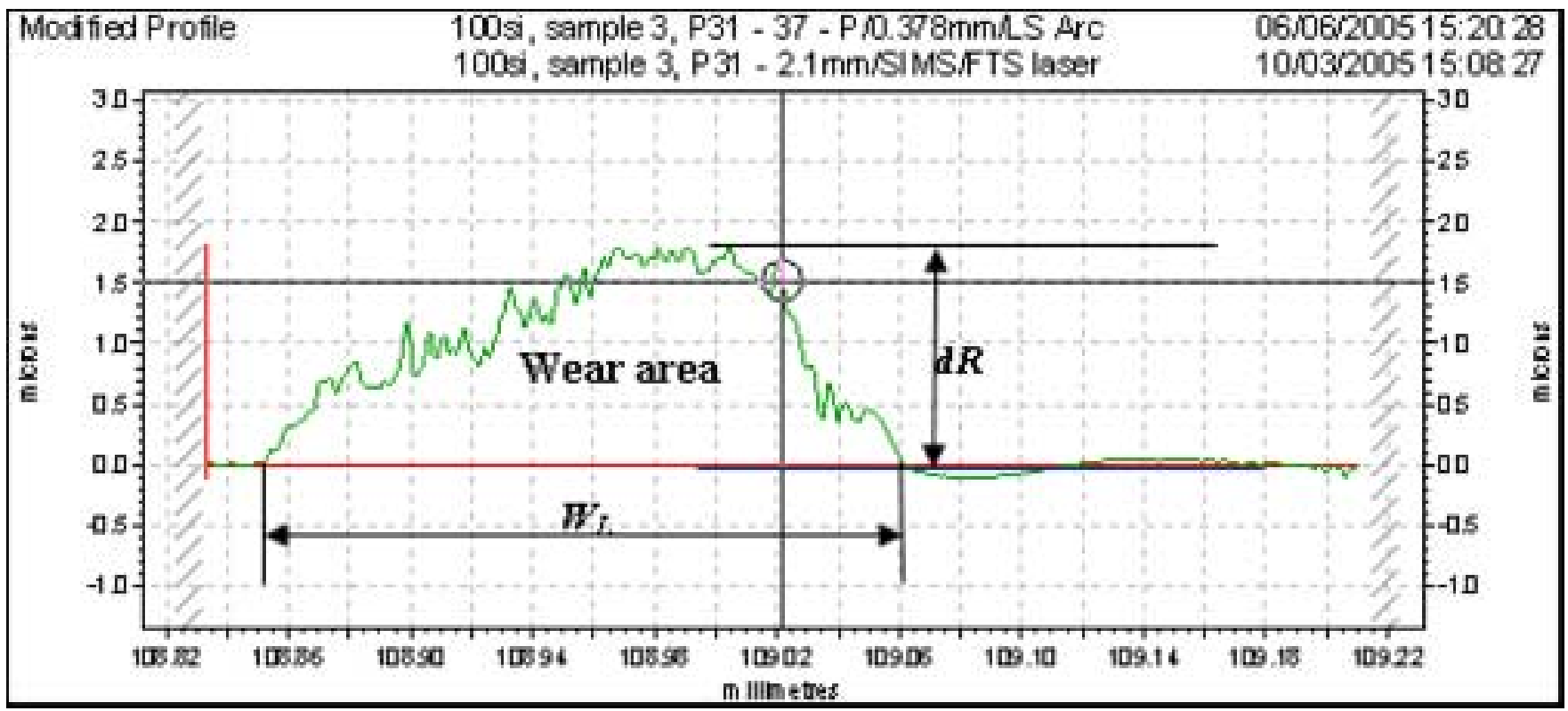


Click here to download high resolution image

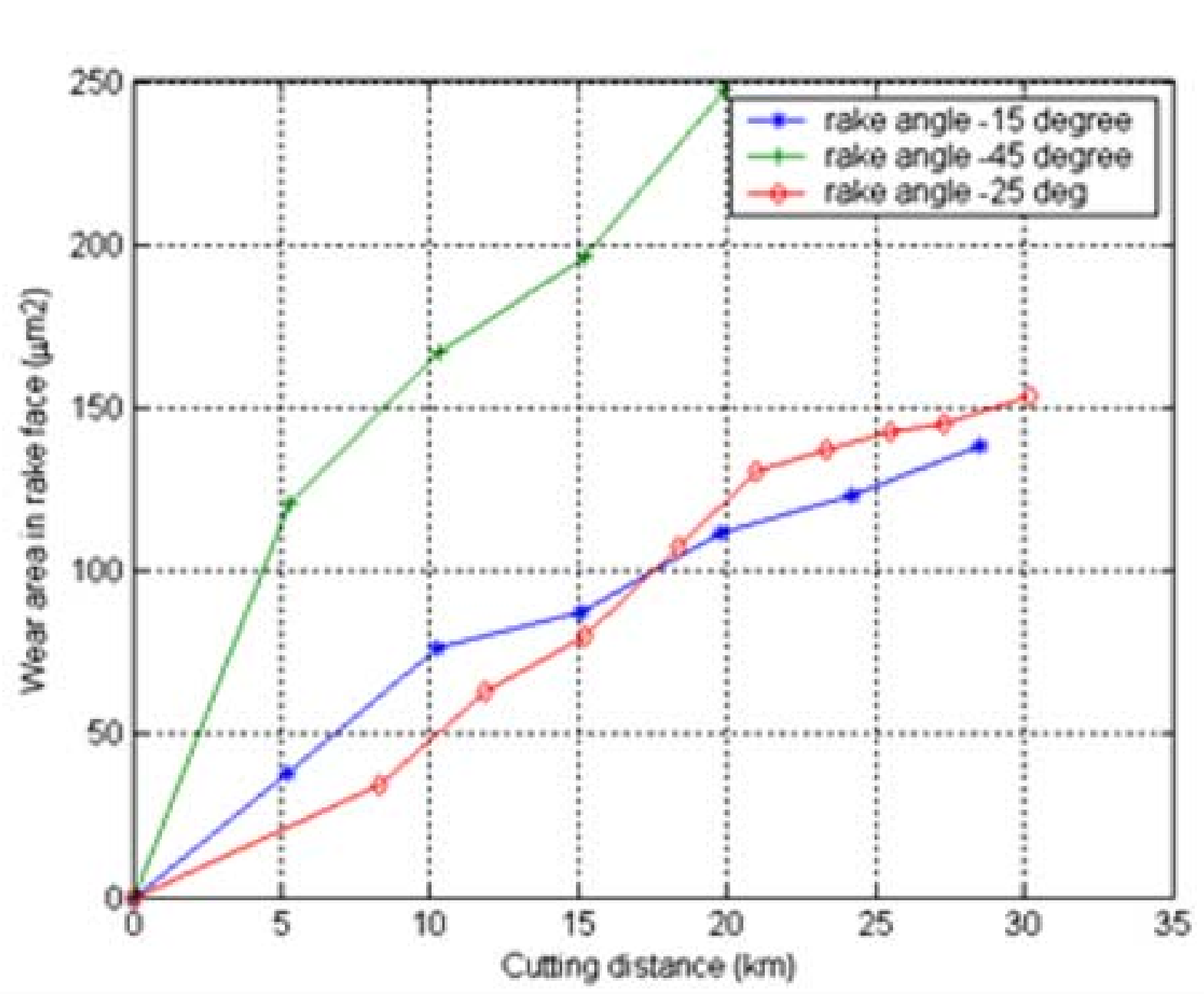

figure 11

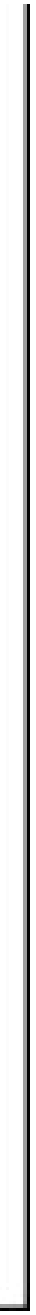


Click here to download high resolution image

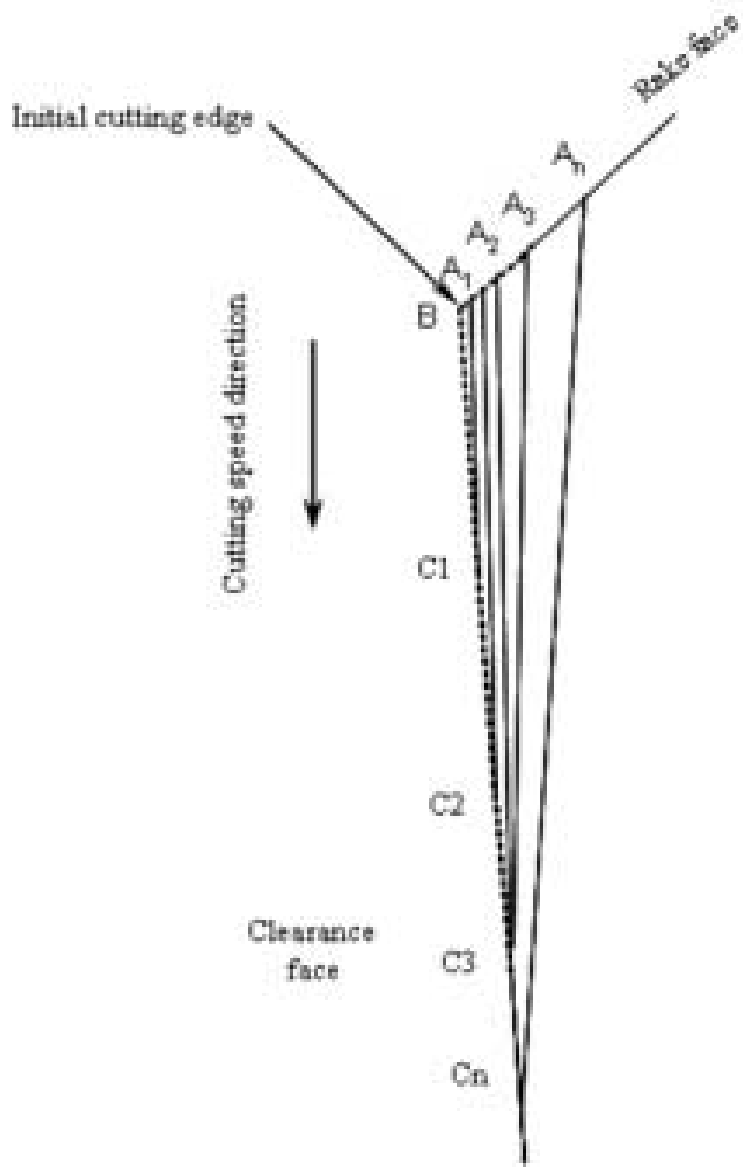




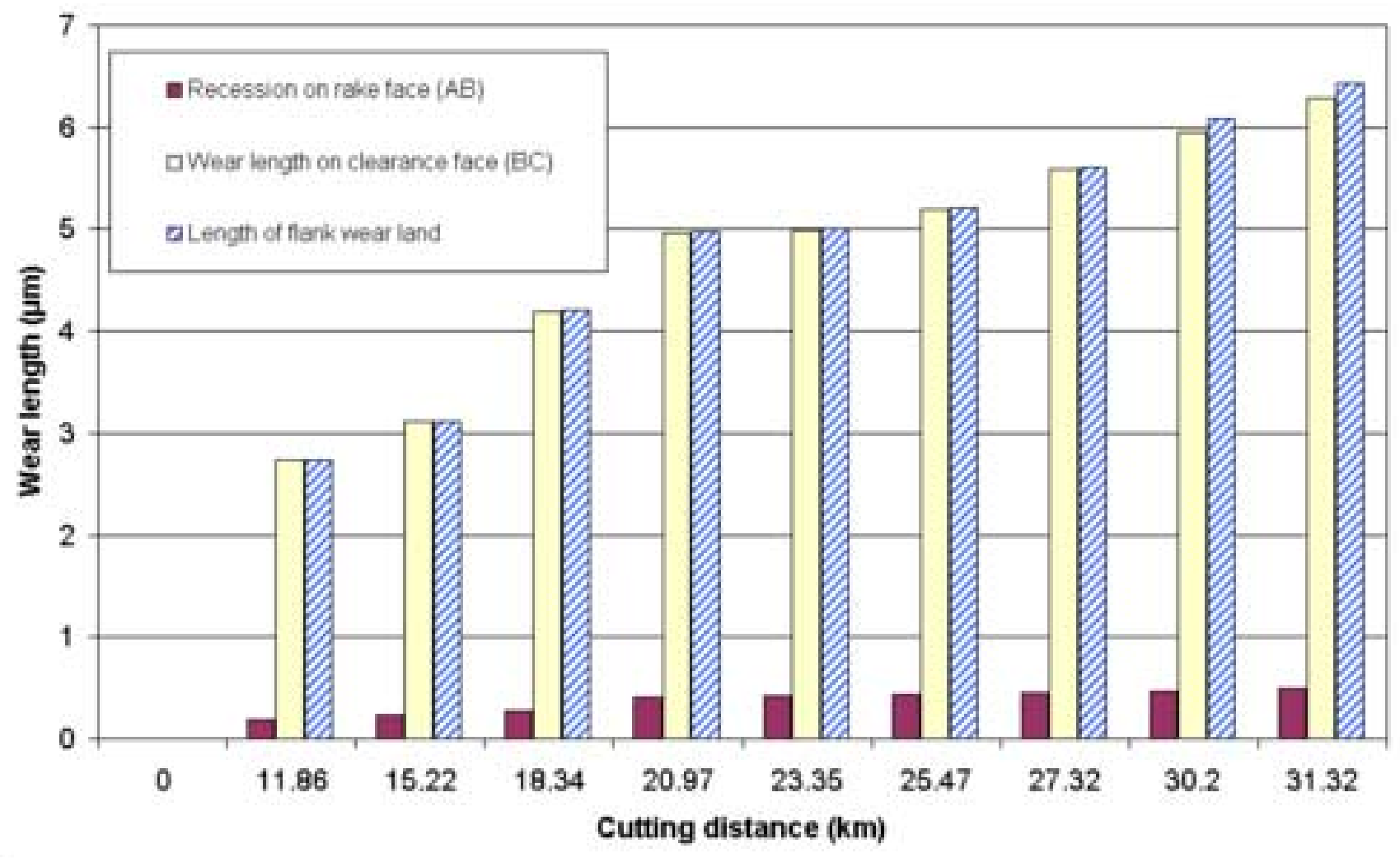




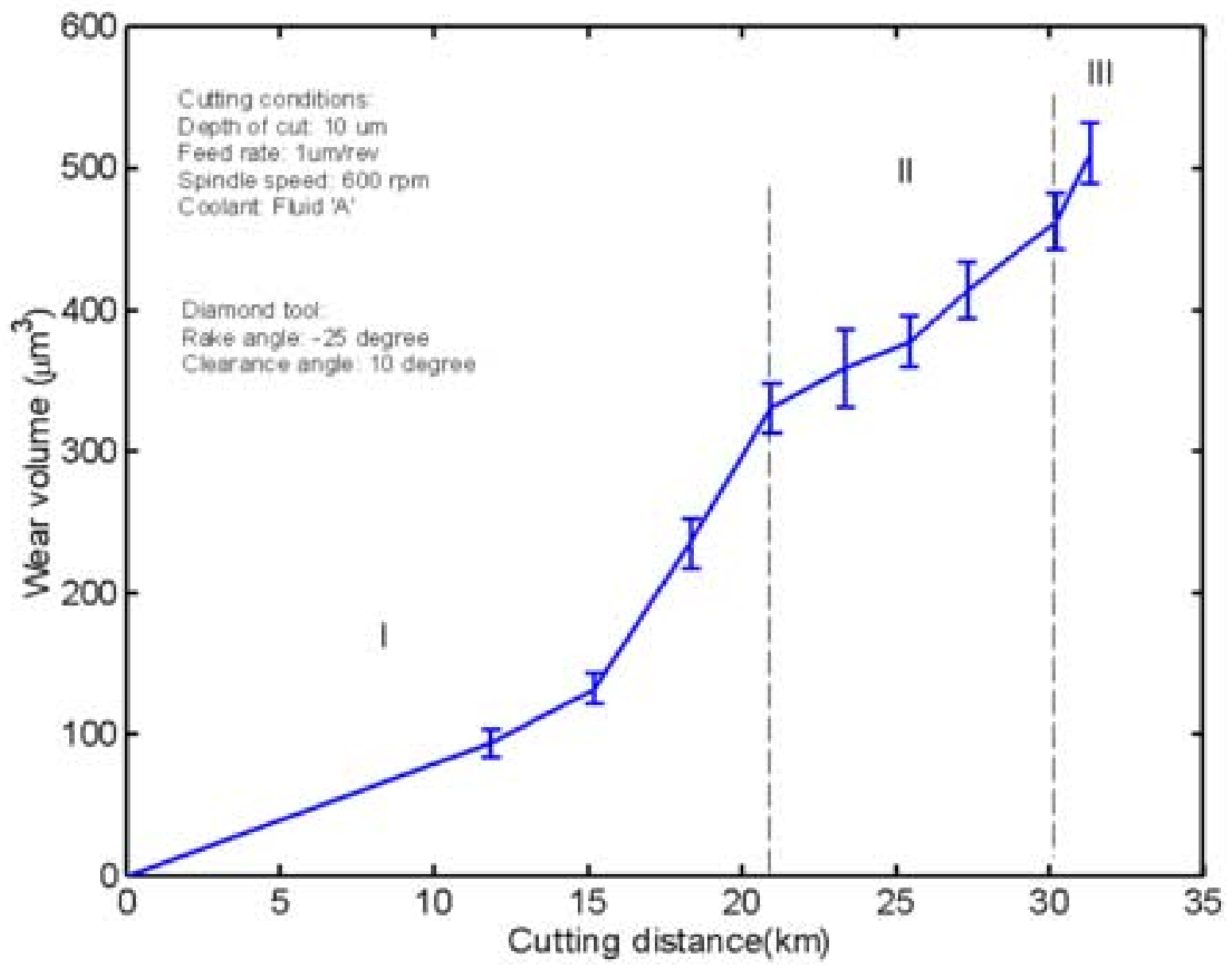




\section{Response to reviewers}

\section{Reviewer 1:}

1. English and grammar have been thoroughly reviewed throughout the document. Many of the original sentences in most of the paragraphs have been rewritten or improved. They are too many to be individually listed. The paper should read easier now.

2. Figure 4 has been removed. Results are now described in a few text lines under section 3.2.

3. It has been clarified how one tool 'outperformed' the others by quantifying in each instance the cutting distance achieved. All sentences where the term 'outperform(ed)' was used have been edited; and this term removed. More quantitative terms have been used instead. The diamond tools used were of identical specification. This has been clarified in section 2.1 ( $2^{\text {nd }}$ paragraph).

4. It has been clarified that each time the tools were used in a new test with a new coolant they were re-lapped to an 'as new' condition (paragraph 3 of section 3.1).

Reviewer 2:

1. A new table (table 1) detailing some important physical properties of the coolants used has been added.

2. The feed-rate at which the plunge cuts were performed has been clarified in section 2.1 ( $6^{\text {th }}$ paragraph). This sentence now reads '...to a depth of $20 \mu \mathrm{m}$ at a $0.2 \mu \mathrm{m} / \mathrm{rev}$ in-feed rate...').

3. Particulars of the procedure for measuring roughness and the determination of the brittle fracture transition have been further detailed in section 3.2 ( $2^{\text {nd }}$ paragraph). A $10 \mathrm{~nm} R$ a value has been used as reference along the most severely fractured arms.

4. All force results presented are concerned only with the normal cutting force. This has been clarified in section 3.1 ( $5^{\text {th }}$ paragraph). All other instances related to force measurement and results have been edited to indicate that these relate to normal cutting force.

5. Scatter bars have been added to figure 15 . 